\title{
Effect of Façade Thickness on Daylight Performance in a Reference Office Building
}

\author{
Rizki A. Mangkuto ${ }^{1}$, Randy Frans Fela ${ }^{2}$, Sentagi S. Utami ${ }^{2}$ \\ ${ }^{1}$ Building Physics Research Group, Faculty of Industrial Technology, Institut Teknologi Bandung, \\ Bandung, Indonesia \\ ${ }^{2}$ Department of Nuclear Engineering and Engineering Physics, Faculty of Engineering, \\ Universitas Gadjah Mada, Yogyakarta, Indonesia
}

\begin{abstract}
Current daylighting simulation practice often ignores the importance of façade thickness, despite its real influence on the total building performance. This research therefore aims to determine the effect of various facade thickness on daylight performance in a simulated reference office. An isolated reference office with an unglazed opening on one of the short façade was taken as case study, modelled and simulated in Radiance and Daysim, using weather data of Bandung, Indonesia. The thickness of the window façade was varied within $0.05 \sim 0.50 \mathrm{~m}$, and the following daylight metrics were determined: average daylight factor, spatial daylight autonomy, spatial useful daylight illuminance, simplified daylight glare probability on selected viewpoints, and annual lighting energy demand. Results suggest that variation of façade thickness yields different impacts, which is largely significant on the average daylight factor, but is subtler on the climate-based daylight metrics and lighting energy demand.
\end{abstract}

\section{Introduction}

Daylighting in buildings has long been understood as one of the most important features of indoor environmental quality. The provision of daylight in buildings, if done properly, may reduce the electrical energy demand, while creating a positive environment in terms of comfort, health and well-being (e.g. Aries et al., 2010; Bluyssen et al., 2011; Aries et al., 2015).

Since the application of daylighting in buildings typically involves a conflicting objective, for instance in terms of thermal versus visual comfort (e.g. Ochoa et al., 2012; Goia et al., 2013; Zhang et al., 2017), it is now not uncommon to perform computational modelling and simulation to predict the performance of the proposed daylighting systems. However, current practice in daylighting simulation often ignores or underestimates the impact of façade thickness on the simulated daylight performance. In modelling interior space for daylighting simulation, the uncertainty in façade thickness is often assumed negligible.

Practical observations on several CAD programs/ software that are commonly employed to model and/or simulate daylighting, i.e. SketchUp, Rhinoceros, DIALux, show that the default value assigned for façade thickness is zero. In other words, the façade is assumed infinitely thin, unless the user specifies otherwise. Other software, e.g. VELUX Daylight Visualizer assigns default value of $0.300 \mathrm{~m}$ for the wall (façade) thickness. This value is somehow close to the baseline value of façade in the reference office of van Dijk and Platzer (2003), which is $0.355 \mathrm{~m}$. In the reference office of Reinhart et al. (2013), the interior wall thickness (presumably similar with the façade wall thickness) is assumed to be $0.150 \mathrm{~m}$.

Therefore, one may conclude that the assumed 'reference' or 'baseline' value for this quantity is quite diverse. However, to the best of our knowledge, it seems that there are no specific investigations on how critical the uncertainty of this value is, with regard to daylighting performance. Van Dijk and Platzer (2003) proposed some possible variations on the façade thickness, ranging from 0.295 until $0.325 \mathrm{~m}$, but these were given in the context of thermal simulation. Reinhart et al. (2013) investigated the influence of window area on their reference office but did not consider any variation of façade thickness.

Meanwhile, in predicting total building performance simulation, it is important to assign proper values for façade thickness, since it largely influences the heat transfer into and out from the building. For daylighting case, a relatively thick façade may serve the role as static shading device, which can effectively reduce the effective daylight opening area, which will affect the daylight performance and lighting energy demand, hence should not be negligible. There are multiple reasons for choosing different values of façade thickness and these have implications on many aspects of building performance and, consequently, the occupant response. For their reference office, van Dijk and Platzer (2003) had proposed some possible variations on the façade thickness, ranging from 0.295 until $0.325 \mathrm{~m}$, corresponding to the thermal mass and insulation level. In that report, the same reference office was proposed for (day)lighting simulation (in Section 8); but in that section, the importance of assuming façade thickness is not particularly mentioned, thus giving the impression that façade thickness is somehow negligible (which is actually not) in daylighting simulation.

Again, if one wishes to use any of the mentioned programs/software that assume zero façade thickness, the discrepancy with the proposed 'reference' value will presumably be significant, unless the user is completely aware of the issue so that he/she will specify a non-zero value for the façade thickness. Nevertheless, the effect of 
this value selection on the daylighting performance of the building needs to be quantified in a systematic way.

Therefore, this research aims to determine the effect of various façade thickness on daylight performance and lighting energy demand in a simulated reference office, while also considering the impact of window orientation.

\section{Methods}

An isolated building (reference office, adopted from van Dijk and Platzer (2003)) with inner space of $6 \mathrm{~m} \times 4 \mathrm{~m} \times$ $3 \mathrm{~m}$ and a single, unglazed opening measuring $3 \mathrm{~m} \times 1 \mathrm{~m}$ (window-to-wall ratio of $25 \%$ ) on one of the short façade, was taken as the case study. The building was modelled in Radiance and simulated in Daysim, using the weather data of Bandung, Indonesia (6 $\left.6^{\circ} 54^{\prime} 53^{\prime \prime} \mathrm{S}, 107^{\circ} 36^{\prime} 35^{\prime \prime} \mathrm{E}\right)$. The ceiling, wall, and floor reflectance was respectively $0.8,0.5$, and 0.2 , all were kept constant. The window orientation was varied between north, east, south, and west. The thickness of the window façade was varied from $0.05 \mathrm{~m}$ until $0.50 \mathrm{~m}$, with an interval of $0.05 \mathrm{~m}$ (Figure 1).

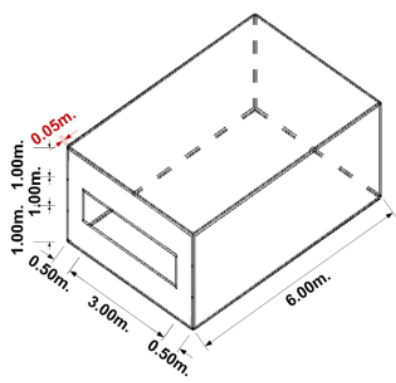

(a)

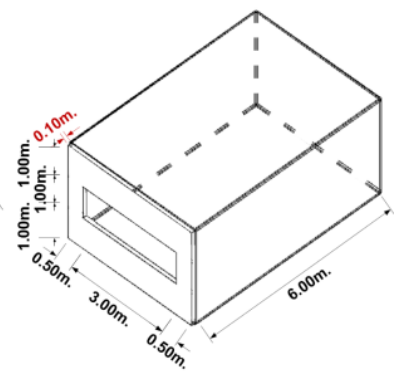

(b)

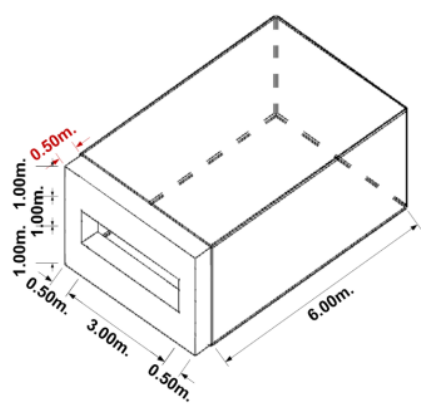

(c)

Figure 1: The modelled building, here shown with the window façade of (a) 0.05, (b) 0.10, and (c) $0.50 \mathrm{~m}$ thick.

\section{Daylight metrics}

Daylight performance in the building was evaluated by observing the following daylight metrics as determined from the simulation:

1. Average daylight factor $\left(\mathrm{DF}_{\mathrm{av}}\right)$, which is the spatially averaged daylight factor (DF) at the defined sensor points (Figure 2) on the workplane height $(0.75 \mathrm{~m}$ above the floor). The DF itself is defined as the ratio between internal $\left(E_{\mathrm{int}}\right)$ and external $\left(E_{\mathrm{ext}}\right)$ illuminance measured simultaneously under the standard CIE overcast sky, so that:

$$
\mathrm{DF}=\frac{E_{\text {int }}}{E_{\text {ext }}} \times 100 \%
$$

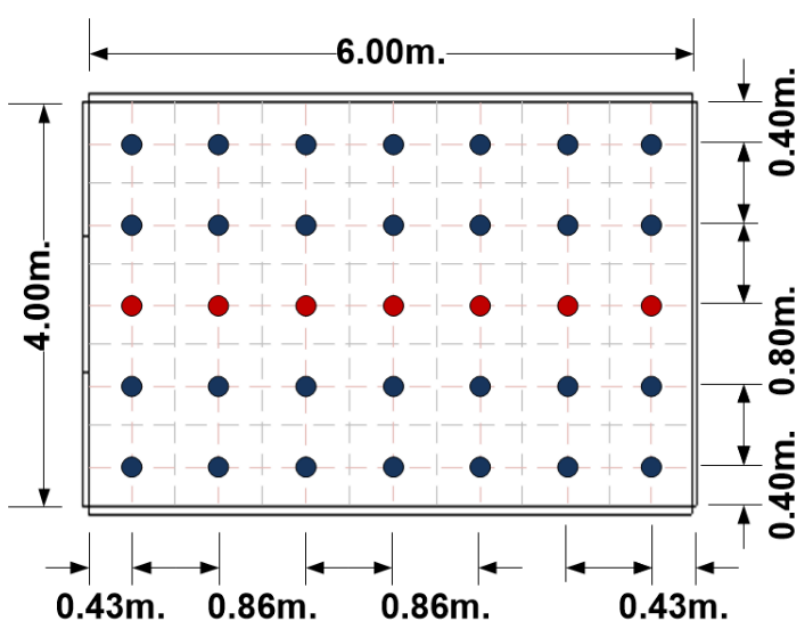

Figure 2: Floor plan of sensor points on the interior space.

2. Spatial daylight autonomy $\left(\mathrm{sDA}_{300 / 50 \%}\right)$, which is the spatial fraction of the floor (or workplane) area having daylight autonomy of $300 \mathrm{~lx}\left(\mathrm{DA}_{300}\right)$ at least $50 \%$ of the annual occupied time $T$ (IES, 2013), so that:

$$
\mathrm{DA}_{300}=\frac{t_{E \geq 3001 \mathrm{x}}}{T} \times 100 \%
$$

and:

$$
\mathrm{sDA}_{300 / 50 \%}=\frac{A_{\mathrm{DA}_{300} \geq 50 \%}}{A_{\text {total }}} \times 100 \% \approx \frac{n_{\mathrm{DA}_{300} \geq 50 \%}}{n_{\text {total }}} \times 100 \%
$$

where $A$ is the area, which is usually approximated by the number of sensor points $n$, in this case also referring to Figure 2.

3. Spatial useful daylight illuminance (sUDI-a50\% and sUDI- s $_{5 \%}$ ), which is the spatial fraction of the floor (or workplane) area having useful daylight autonomy within range of respectively 100 2000 1x (UDI $100 \sim 2000$, or UDI-a) and > $2000 \mathrm{~lx}\left(\mathrm{UDI}_{>2000}\right.$, or UDI-e) at least $50 \%$ of the annual occupied time $T$, so that:

$$
\begin{gathered}
\mathrm{UDI}_{100 \sim 2000}=\frac{t_{100 \leq E \leq 2000 \mathrm{~lx}}}{T} \times 100 \% \\
\mathrm{UDI}_{>2000}=\frac{t_{E>2000 \mathrm{~lx}}}{T} \times 100 \%
\end{gathered}
$$

and:

$$
\begin{aligned}
\mathrm{sUDI}^{-\mathrm{a}_{50 \%}} & \approx \frac{n_{\mathrm{UDI}_{100-2000} \geq 50 \%}}{n_{\text {total }}} \times 100 \% \\
\text { sUDI-e }_{50 \%} & \approx \frac{n_{\mathrm{UDI}_{22000} \geq 50 \%}}{n_{\text {total }}} \times 100 \%
\end{aligned}
$$

Note that the use of these sUDI metrics are modified by the authors, since specific standards applying them are not yet available. The temporal threshold of $50 \%$ can however be drawn in parallel with the $\mathrm{sDA}_{300 / 50 \%}$ and has been proposed in literature e.g. by Mangkuto et al. (2016). 
The default value of upper threshold for UDI calculation in Daysim is 2000 lx, since the program was mainly developed before the proposal of raising the upper threshold to $3000 \mathrm{~lx}$ was published. In addition, there are some findings from field study in the tropics (e.g. Hirning et al., 2013; 2014; Mangkuto et al., 2016; 2017), suggesting that building occupants in the tropics may be more sensitive to discomfort glare and high illuminance values from daylight, so that smaller value for the upper threshold shall be preferred. Therefore, in this case, the default value of $2000 \mathrm{~lx}$ was assigned as the upper UDI threshold.

4. Simplified daylight glare probability (DGPs), which is the simplified version of the original DGP proposed by Wienold and Christoffersen $(2005 ; 2006)$ :

$$
\begin{aligned}
\text { DGP } & =5.87 \times 10^{-5} E_{v} \\
& +0.0918 \log \left\lfloor 1+\sum_{i=1}^{n}\left(\frac{L_{s, i}^{2} \omega_{s, i}}{E_{v}^{1.87} P_{i}^{2}}\right)\right\rfloor+0.016
\end{aligned}
$$

The DGPs relies only on vertical illuminance $\left(E_{v}\right)$ component, so that:

$$
\text { DGPs }=6.22 \times 10^{-5} E_{v}+0.184
$$

The $E_{v}$ was simulated at the red points in Figure 2, which is located at the room's long axis, at height of $1.5 \mathrm{~m}$ facing directly to the window.

Two DGPs metrics were reported in this study, i.e. the mean annual DGPs at the central point $\left(\operatorname{DGPs}_{(\mathrm{c})}\right)$, and the spatially-averaged mean annual DGPs among the red points in Figure $2\left(\mathrm{DGPs}_{(\mathrm{s})}\right)$.

5. Annual lighting energy demand (ED), which is the total demand for electrical lighting energy in a year for the simulated space, in $\mathrm{kWh} / \mathrm{m}^{2}$.

\section{Simulation settings}

Table 1 displays the assigned simulation parameters in Daysim.

Table 1: Daysim simulation parameters.

\begin{tabular}{|l|c|}
\hline \multicolumn{1}{|c|}{ Parameter } & Value \\
\hline Ambient bounces (ab) & 5 \\
\hline Ambient divisions (ad) & 1000 \\
\hline Ambient super-samples (as) & 20 \\
\hline Ambient resolution (ar) & 300 \\
\hline Ambient accuracy (aa) & 0.1 \\
\hline Limit reflection (lr) & 6 \\
\hline Specular threshold (st) & 0.15 \\
\hline Specular jitter (sj) & 1 \\
\hline Limit weight (lw) & 0.004 \\
\hline Direct jitter (dj) & 0 \\
\hline Direct sampling (ds) & 0.2 \\
\hline Direct relay (dr) & 2 \\
\hline Direct pretest density (dp) & 512 \\
\hline
\end{tabular}

The simulated space is continuously occupied from Monday through Friday at 08.00 until 17.00 hrs, giving the total annual hours of occupancy of 2349 hours. The electric lighting is activated 2370.8 hours per year. The occupants are assumed to perform visual task requiring a minimum workplane illuminance of $300 \mathrm{~lx}$.
Note that the total annual occupancy duration is 2349 hours, corresponding to 261 working days at nine hours (08.00 17.00) each. The annual duration in which electric lighting is activated is calculated with the algorithm of Lightswitch-2002 model (Reinhart, 2004). In a nutshell, the model assumes certain "switch-off probabilities for different times of user absence for a lighting system without controls, with an occupancy sensor", referring to Pigg et al. (1996). For a direct photocell-controlled dimmed lighting system, the weekday profile of the annual mean electric lighting load in the reference office is provided in Figure 8b in Reinhart (2004). The profile suggests some small loads of electric lighting even before (05.00 07.00) and after (18.00 23.00) working hours. Therefore, the annual duration of electric lighting activation is somewhat longer than the total annual occupancy duration.

No additional external nor internal shading device was defined on the façade. The lighting control algorithm is defined in general according to the Lightswitch-2002 model as developed by Reinhart (2004). The electric lighting system has an installed lighting power density (LPD) of $7.25 \mathrm{~W} / \mathrm{m}^{2}$. This value was chosen with reference to Lo Verso et al. (2017), corresponding to the specified workplane illuminance of $300 \mathrm{~lx}$. Note that the Indonesian national standard (BSN, 2000; 2001) suggests LPD of $15 \mathrm{~W} / \mathrm{m}^{2}$ for typical office room, but this was prescribed in the era before the emerging of LED lighting, which now can provide a much lower LPD.

The system is automatically controlled via an on/off occupancy sensor with a delay time of 5 minutes. The dimming system has an ideally commissioned photocell control with a ballast loss factor of $0 \%$, while the lighting system has no standby power per unit area. No dynamic shading device system is assigned for the simulated space.

\section{Results and Discussion}

\section{Trend visualisation}

All metrics obtained from the simulation are displayed in graphs in Figure 3 until 9, as a function of the façade thickness, categorised for the four orientations.

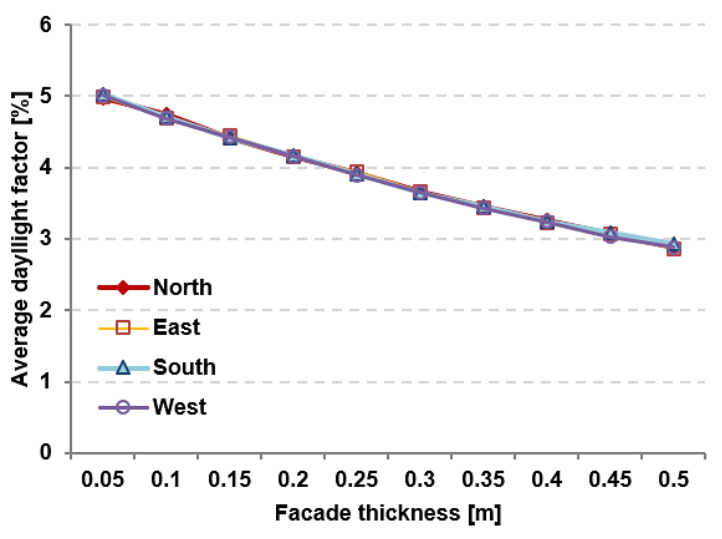

Figure 3: The resulting $D F_{a v}$. 


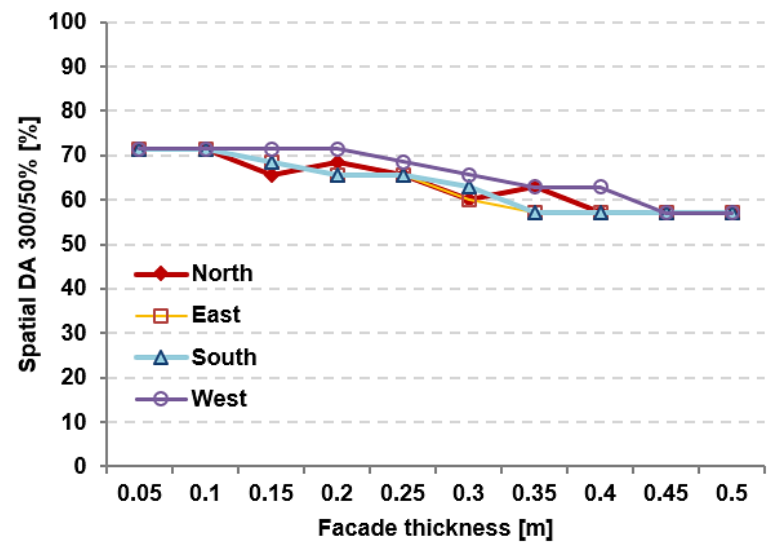

Figure 4: The resulting sDA300/50\%.

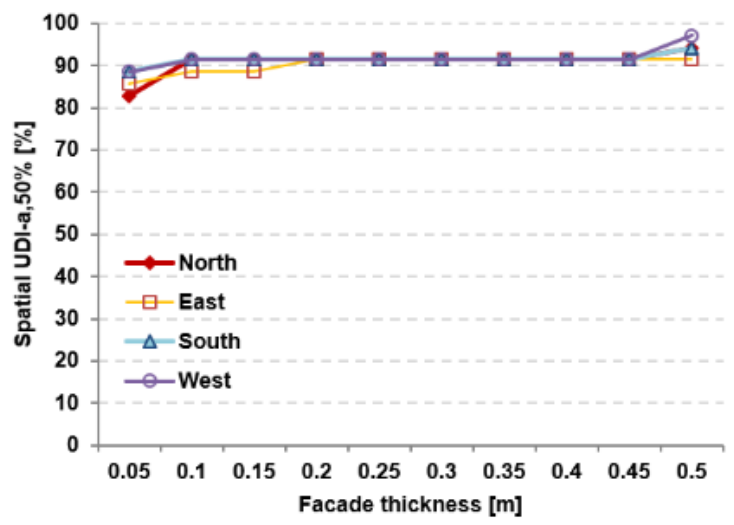

Figure 5: The resulting sUDI- $a_{50 \%}$.

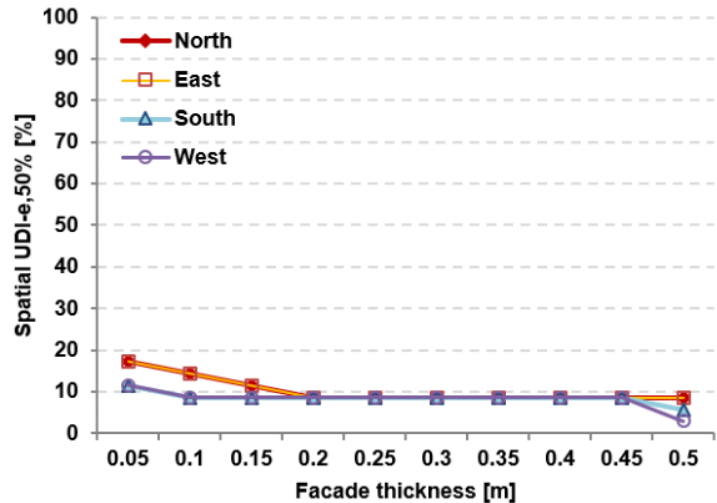

Figure 6: The resulting sUDI-e $50 \%$.

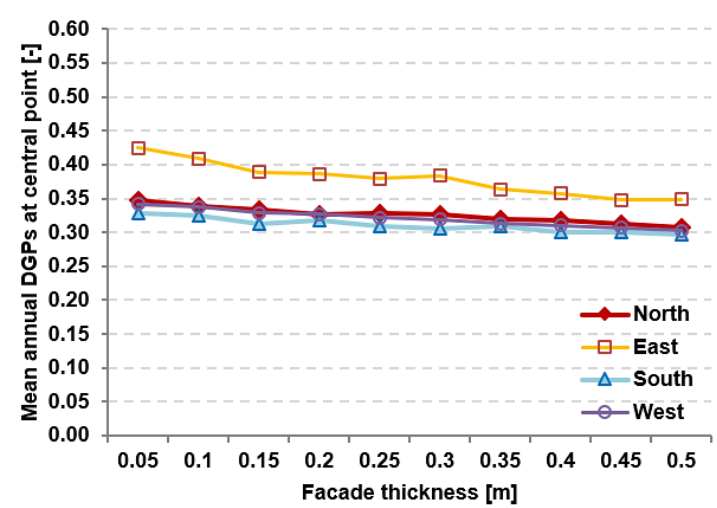

Figure 7: The resulting $D G P s_{(c)}$.

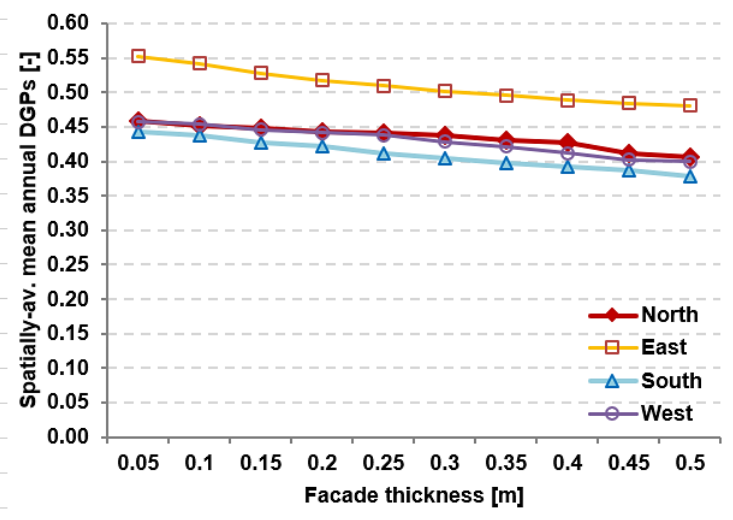

Figure 8: The resulting $D G P s_{(s)}$

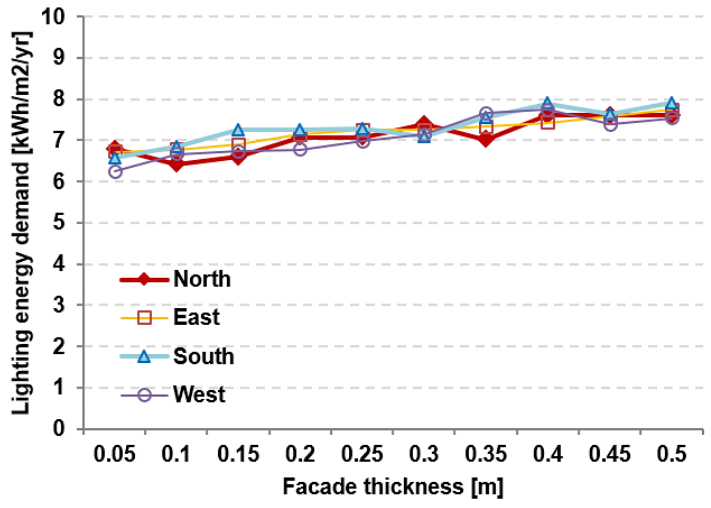

Figure 9: The resulting ED.

Among all of the compared metrics, it is observed that the $\mathrm{DF}_{\mathrm{av}}$ is the only one that constantly changes (decreases in this case) as the façade become thicker (Figure 3). Obviously, since DF is defined for the CIE overcast sky that is rotationally symmetrical, the impact of façade orientation on the metric is virtually negligible. While DF value conceptually does not depend on façade orientation, Daysim implements daylight coefficients from Tregenza sky elements (based on Perez all weather sky) in its calculation. Therefore, there shall be a confirmation whether the correct algorithm has been implemented in computing DF value, e.g. by reducing the sky model to standard overcast or by including only the diffuse sky luminance. This was done in this study by testing various orientations while observing the average DF. The results in Figure 3 clarifies that the obtained DF in this case is indeed independent of orientation.

When averaged over the orientations, a linear relation $\left(R^{2}\right.$ $=0.9926)$ between $\mathrm{DF}_{\mathrm{av}}[\%]$ and the façade thickness $(x$ [m]) can be obtained, which reads:

$$
\mathrm{DF}_{\mathrm{av}}=-4.6967 x+5.1421
$$

That is, for every $0.05 \mathrm{~m}$ increase of the façade thickness, the $\mathrm{DF}_{\mathrm{av}}$ can be expected to reduce by a linear difference of approximately $0.235 \%$. It should be noted that Equation 10 is valid only for this case (particularly the opening area and configuration). Different opening and/or room size may result in a different relationship. 
As for the spatially-evaluated climate based daylight metrics (CBDM), i.e. sDA $300 / 50 \%$, sUDI-a50\%, and sUDI$\mathrm{e}_{50 \%}$, it is found that increasing the façade thickness does not linearly increase nor decrease the metrics. Some fluctuations of $\mathrm{sDA}_{300 / 50 \%}$ exist as the façade becomes thicker, and slight differences occur between the orientations (Figure 4), but the general tendency is the $\mathrm{sDA}_{300 / 50 \%}$ becomes smaller as the façade goes thicker, thus roughly in line with the $\mathrm{DF}_{\mathrm{av}}$ trend.

With regard to sUDI-a50\%, and sUDI- $\mathrm{e}_{50 \%}$, increasing the façade thickness at certain range, i.e. 0.10 until $0.45 \mathrm{~m}$ for the former, and 0.20 until $0.45 \mathrm{~m}$ for the latter, gives very little or entirely no impact (Figure 5 and 6). At these ranges, the orientation also has got no influence. Beyond these ranges, the difference in the resulting metrics becomes noticeable again.

At the smallest thickness $(0.05 \mathrm{~m})$, the sUDI-a $a_{50 \%}$ is at minimum, whereas the sUDI- $\mathrm{e}_{50 \%}$ is at maximum. The opposite is true at the largest thickness $(0.50 \mathrm{~m})$. This suggests that a very thin façade correspond to excessive amount of daylight (sUDI- $\mathrm{e}_{50 \%} \approx 17 \%$ at north orientation, $11 \%$ at west), and a thick façade can significantly reduce it (sUDI-e $50 \% \approx 6 \%$ at north, $3 \%$ at west). Consequently, the actually 'useful' daylit area (sUDI-a $50 \%$ ) is increased from around $83 \%$ at north and $89 \%$ at west, into around $95 \%$ and $97 \%$ at the respective orientations.

Also as a consequence, the $\mathrm{DGPs}_{(\mathrm{c})}$ and $\mathrm{DGPs}_{(\mathrm{s})}$ decrease as the façade becomes thicker, though the difference between the highest (at $0.05 \mathrm{~m}$ thickness) and the lowest DGPs value (at $0.50 \mathrm{~m}$ thickness) at any given orientation is not more than 0.07 (Figure 7 and 8). One-way ANOVA to test the effect of orientation on $\operatorname{DGPs}_{(\mathrm{c})}$ and $\mathrm{DGPs}_{(\mathrm{s})}$ suggests this choice of input is significantly influential to the output (Table 2 and 3).

Table 2: Result of one-way ANOVA testing the effect of orientation on $D G P s_{(c)}$.

\begin{tabular}{|l|c|c|c|c|c|}
\hline \multicolumn{1}{|c|}{ Source } & SS & df & MS & $\boldsymbol{F}$ & $\boldsymbol{p}$ \\
\hline Between group & 0.0282 & 3 & 0.0094 & 35.2 & $<0.001$ \\
\cline { 1 - 4 } Within group & 0.0096 & 36 & 0.0003 & & \\
\hline Total & 0.0378 & 39 & & & \\
\hline
\end{tabular}

Table 3: Result of one-way ANOVA testing the effect of orientation on $D G P s_{(s)}$.

\begin{tabular}{|l|c|c|c|c|c|}
\hline \multicolumn{1}{|c|}{ Source } & SS & df & MS & $\boldsymbol{F}$ & $\boldsymbol{p}$ \\
\hline Between group & 0.0576 & 3 & 0.0192 & 42.4 & $<0.001$ \\
\cline { 1 - 4 } Within group & 0.0163 & 36 & 0.0004 & & \\
\hline Total & 0.0739 & 39 & & & \\
\hline
\end{tabular}

In Tables 2 and 3, SS is the sum of square, df: degree of freedom, MS: mean square, $F$ : the statistical test value having $F$ distribution, basically defined as the ratio of between-group-variability to within-group-variability, $p$ : the probability or significance value that when the null hypothesis is true, the statistical summary would be greater than or equal to the actual observed results.
The Tukey HSD (honestly significant different) test, which is a single-step multiple comparison procedure and statistical test (Tukey, 1949), was performed on the ANOVA results. This test is typically conducted after performing an ANOVA (post-hoc analysis) to find means that are significantly different from each other. In this test, all pairs of means are compared, based on a studentised range distribution $(Q)$ that has a similar distribution to the $t$ distribution.

The post-hoc Tukey HSD test reveals that the east orientation yields significantly higher DGPs compared to the other three orientations (Table 4). This can be explained by the fact that east façade receives more solar radiation before noon in which the sky is mostly clear and rain is unlikely to occur. Meanwhile, there is higher chance of rain during afternoon, as is commonly found in the tropics, resulting in a somewhat lower solar radiation on the west façade.

Table 4: Result of Tukey HSD test on orientations with regard to $D G P s_{(c)}$ and $D G P s_{(s)}$

\begin{tabular}{|l|r|l|c|l|}
\hline \multirow{2}{*}{\multicolumn{1}{|c|}{ Pair }} & \multicolumn{2}{|c|}{ w.r.t. DGPs(c) } & \multicolumn{2}{c|}{ w.r.t. DGPs $(\mathbf{s})$} \\
\cline { 2 - 5 } & \multicolumn{1}{c|}{$\boldsymbol{Q}$} & $\boldsymbol{p}$ & $\boldsymbol{Q}$ & \multicolumn{1}{c|}{$\boldsymbol{p}$} \\
\hline North v East & 10.36 & $\mathbf{0 . 0 0 1} *$ & 11.13 & $\mathbf{0 . 0 0 1} *$ \\
\hline North v South & 3.01 & 0.163 & 3.78 & 0.052 \\
\hline North v West & 0.97 & 0.900 & 0.77 & 0.900 \\
\hline East v South & 13.38 & $\mathbf{0 . 0 0 1} *$ & 14.91 & $\mathbf{0 . 0 0 1} *$ \\
\hline East v West & 11.33 & $\mathbf{0 . 0 0 1}^{*}$ & 11.91 & $\mathbf{0 . 0 0 1}^{*}$ \\
\hline South v West & 2.04 & 0.482 & 3.00 & 0.164 \\
\hline
\end{tabular}

*significant at $95 \%$ or higher confidence level

It can also be observed that DGPs at north orientation is higher than that at south, which is logical since the simulated location of Bandung, Indonesia is at the southern hemisphere $\left(6^{\circ} 54^{\prime} 53^{\prime \prime} \mathrm{S}\right)$, even though is very close to the equator. Chance of precipitation again plays an important role here: the smallest amount of rain (on average $68 \sim 77 \mathrm{~mm}$ of precipitation (Climate-Data.org, 2018)), occurs in the middle of the year (June to August), when the north façade is exposed to direct sunlight. During the beginning and end of the year, the chance of rain is much higher (217 291 $\mathrm{mm}$ of precipitation (Climate-Data.org, 2018)), thus reducing the amount of direct sunlight received on the south façade. These findings are in line with those reported by Mangkuto et al. (2016), also for the climate of Bandung, highlighting the fact that the impact of façade orientation on daylight metrics is negligible, except for DGPs.

Lastly, the influence of façade thickness on lighting energy demand is also sensible, though there are some fluctuations across the way (Figure 9). Orientation does have some influence on the obtained metric, though much less compared to DGPs. Generally, thicker façade corresponds to higher $\mathrm{ED}$, varying from roughly 6.5 $\mathrm{kWh} / \mathrm{m}^{2} / \mathrm{yr}$ at $0.05 \mathrm{~m}$ thickness, to roughly $7.5 \mathrm{kWh} / \mathrm{m}^{2} / \mathrm{yr}$ at $0.50 \mathrm{~m}$ thickness. 


\section{Impact of façade thickness}

To objectively compare the impact of façade thickness variation on all metrics, the coefficient of variance $(\mathrm{CV})$, i.e. ratio between standard deviation and mean, were calculated across the façade thickness, for the four orientations separately. Table 5 displays the results, together with the averaged value over all orientations.

Table 5: Coefficient of variation of all metrics, calculated across the façade thickness, categorised based on orientations.

\begin{tabular}{|c|c|c|c|c|c|}
\hline Metric & North & East & South & West & Average \\
\hline $\mathrm{DF}_{\mathrm{av}}$ & 0.18 & 0.19 & 0.18 & 0.19 & 0.19 \\
\hline $\mathrm{sDA}_{300 / 50 \%}$ & 0.09 & 0.10 & 0.09 & 0.09 & 0.09 \\
\hline sUDI-a $50 \%$ & 0.03 & 0.02 & 0.01 & 0.02 & 0.02 \\
\hline sUDI-e $_{50 \%}$ & 0.30 & 0.30 & 0.16 & 0.25 & 0.25 \\
\hline $\mathrm{DGPs}_{(\mathrm{c})}$ & 0.04 & 0.07 & 0.03 & 0.04 & 0.04 \\
\hline $\mathrm{DGPs}_{(\mathrm{s})}$ & 0.04 & 0.05 & 0.05 & 0.05 & 0.05 \\
\hline $\mathrm{ED}$ & 0.06 & 0.05 & 0.06 & 0.07 & 0.06 \\
\hline
\end{tabular}

It is found that on average, the largest $\mathrm{CV}$ values are given by sUDI-e $50 \%(0.25), \mathrm{DF}_{\mathrm{av}}(0.19), \mathrm{sDA}_{300 / 50 \%}(0.09)$, and $\mathrm{ED}$ (0.06); whereas the CV for the remaining metrics are not larger than 0.05. One-way ANOVA to test the effect of façade thickness on those aforementioned three metrics reveals that the influence of thickness is indeed significant (Table 6).

Table 6: Result of one-way ANOVA testing the effect of façade thickness on $D F_{a v}, s D A_{300 / 50 \%}, s U D I-e_{50 \%}$ and $E D$.

\begin{tabular}{|c|c|r|r|c|}
\hline Metric & Source & \multicolumn{1}{c|}{ MS } & $\boldsymbol{F}$ & $\boldsymbol{p}$ \\
\hline \multirow{2}{*}{$\mathrm{DF}_{\mathrm{av}}$} & Between group & 18.345 & 5.737 & $<0.001$ \\
\cline { 2 - 4 } & Within group & 3.197 & & \\
\hline \multirow{2}{*}{ SDA $_{300 / 50 \%}$} & Between group & 131.09 & 31.59 & $<0.001$ \\
\cline { 2 - 5 } & Within group & 4.15 & & \\
\hline \multirow{2}{*}{ sUDI-e $50 \%$} & Between group & 2.0370 & 4851 & $<0.001$ \\
\cline { 2 - 3 } & Within group & 0.0004 & & \\
\hline \multirow{2}{*}{$\mathrm{ED}$} & Between group & 0.626 & \multirow{2}{*}{14.80} & $<0.001$ \\
\cline { 2 - 3 } & Within group & 0.042 & & \\
\hline
\end{tabular}

Tukey HSD test was performed to group the thickness values based on their significance level, with regard to the four aforementioned metrics. The mean values across orientation are plotted in Figure 10 until 13, as a function of façade thickness. In those figures, error bars represent the $95 \%$ confidence interval. Based on the Tukey HSD test, the mean of $\mathrm{DF}_{\mathrm{av}}$ can be clustered into ten significant groups (Figure 10), i.e. each value of thickness yields a significantly different $\mathrm{DF}_{\mathrm{av}}$ to all other thickness values, since there is zero impact from façade orientation, hence the error bars do not overlap each other. Therefore, it can be concluded that modifying the façade thickness at 0.05 $\mathrm{m}$ interval will result in a statistically significant reduction of the $\mathrm{DF}_{\mathrm{av}}$.

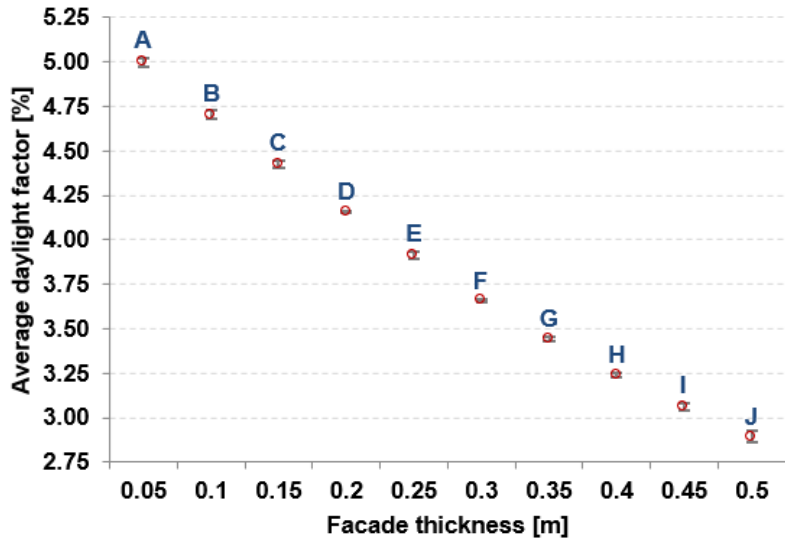

Figure 10: Mean DF av across façade thickness, clustered into ten significant groups.

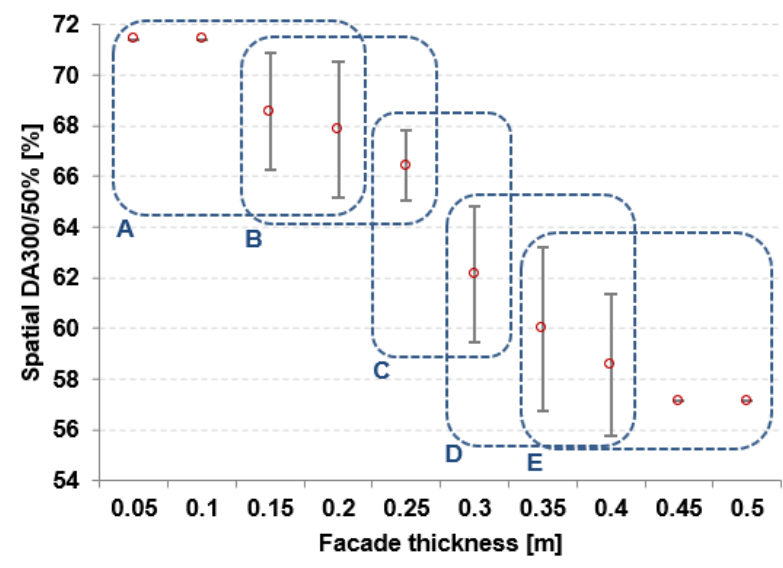

Figure 11: Mean sDA $300 / 50 \%$ across façade thickness, clustered into five significant groups.

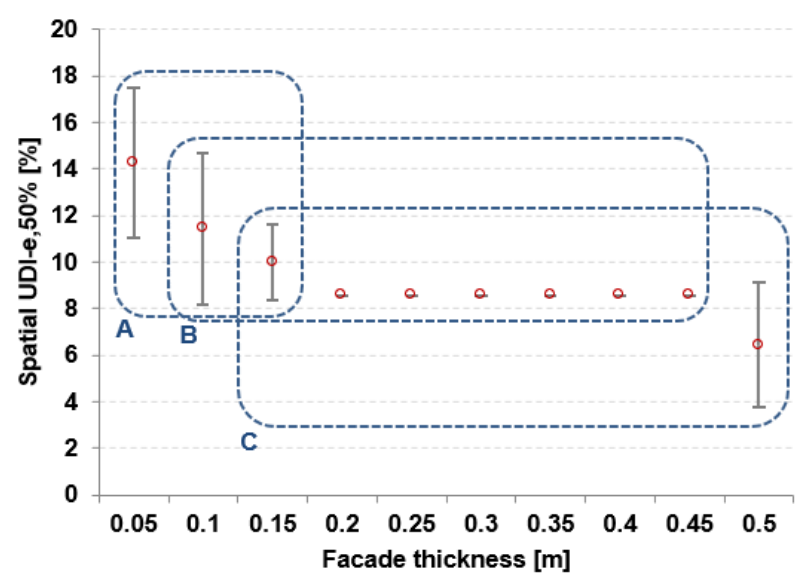

Figure 12: Mean sUDI-e $50 \%$ across façade thickness, clustered into three significant groups. 


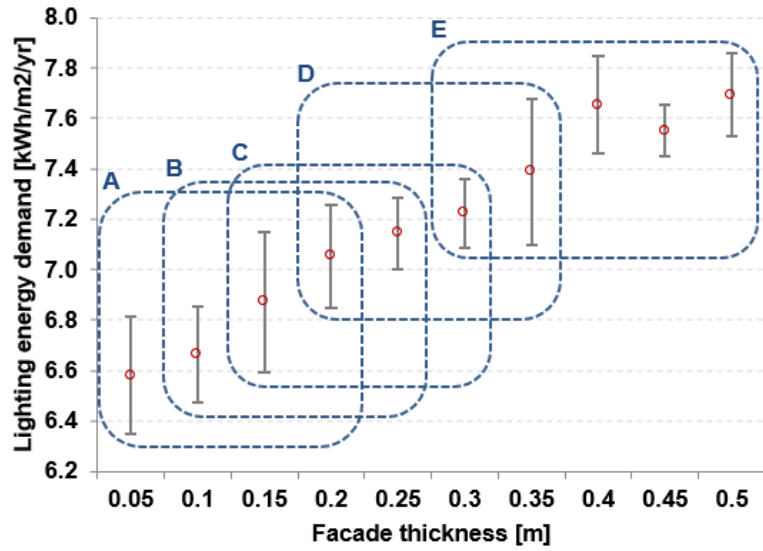

Figure 13: Mean ED across façade thickness, clustered into five significant groups.

As for $\mathrm{DA}_{300 / 50 \%}$, sUDI-e $50 \%$, and ED, only three (A, B, C) or five (A, B, C, D, E) significant groups can be assigned to the ten values of thickness, thus is considerably less than the number of significant groups with regard to $\mathrm{DF}_{\mathrm{av}}$. There are also some large overlaps between consecutive thickness values, so that some of the resulting mean of the metrics can be placed in two or even three significant groups (Figure 11 until 13). Uncertainties due to variation of façade orientation are not constant across the thickness, but among the discussed four metrics, the most consistent uncertainties are found for the ED.

The presented results are limited by the choice of climate, which in this case is the tropical one. However, the results may be considered to some extent as a guideline in selecting appropriate value of façade thickness, while predicting the impact it may yield on various daylight metrics and lighting energy demand. This can be useful not only during the design phase, but also when the building is operational, for instance if a certain type of external shading or outer skin façade is to be added or attached to the existing construction. Follow-up of this study can therefore be directed towards assessing the investigated effect on real building spaces, and how to further optimise it.

\section{Conclusion}

Based on the simulation results, variation of façade thickness is found to yield different impacts on the daylighting performance indicators and lighting energy demand. The impact is largely significant on average daylight factor $\left(\mathrm{DF}_{\mathrm{av}}\right)$ with no effect of façade orientation, as expected. The $\mathrm{sDA}_{300 / 50 \%}$ tends to become smaller as the façade goes thicker, but sUDI-a $50 \%$ and sUDI- $\mathrm{e}_{50 \%}$ may keep constant for a certain range of façade thickness, i.e. 0.20 until $0.45 \mathrm{~m}$.

The DGPs $\mathrm{s}_{(\mathrm{c})}$ and DGPs $\mathrm{s}_{(\mathrm{s})}$ decrease as the façade becomes thicker, though the difference between the highest and the lowest DGPs value at any given orientation is not more than 0.07. It is observed however that the east orientation yields significantly higher DGPs compared to the other three orientations, due to high annual solar radiation and low precipitation in the particular exposure time.
Each façade thickness value yields a significantly different $\mathrm{DF}_{\mathrm{av}}$, but no more than five significant groups can be assigned to the remaining metrics. Thus, the impact of varying façade thickness is the largest on $\mathrm{DF}_{\mathrm{av}}$ and is somewhat subtler on the climate-based daylight metrics and lighting energy demand.

\section{Acknowledgement}

This research was supported by the Ministry of Research, Technology, and Higher Education of the Republic of Indonesia, through the 2019 Applied Research Program (PTUPT), and by the Institute of Research and Community Service of Institut Teknologi Bandung (LPPM ITB), through the 2019 Multidisciplinary Research Program. We gratefully acknowledge the funding from USAID through the SHERA program - Centre for Development of Sustainable Region (CDSR).

\section{References}

Aries, M.B.C., Veitch, J.A., Newsham, G.R. (2010). Windows, view, and office characteristics predict physical and psychological discomfort. Journal of Environmental Psychology 30(4), 533-541.

Aries, M.B.C., Aarts, M.P.J., van Hoof, J. (2015). Daylight and health: A review of the evidence and consequences for the built environment, Lighting Research and Technology 47(1), 6-27.

Badan Standardisasi Nasional (BSN) (2000). SNI 036197-2000: Konservasi energi pada sistem pencahayaan. [in Indonesian: Energy conservation in lighting systems]

Badan Standardisasi Nasional (BSN) (2001). SNI 036575-2001: Tata cara perancangan sistem pencahayaan buatan pada bangunan gedung. [in Indonesian: Design guidelines for artificial lighting system in buildings]

Bluyssen, P.M., Aries, M.B.C., van Dommelen, P. (2011). Comfort of workers in office buildings: The European HOPE project. Building and Environment 46(1), 280-288.

Climate-Data.org. (2018). Climate Bandung - Bandung Weather by Months // Weather Averages. https://en.climate-data.org/asia/indonesia/west-java/ bandung-3246/\#climate-graph. Accessed on 13 December 2018.

Goia, F., Haase, M., Perino, M. (2013). Optimizing the configuration of a façade module for office buildings by means of integrated thermal and lighting simulations in a total energy perspective. Applied Energy 108, 515-527.

Hammad, F., Abu-Hijleh, B. (2010). The energy saving potential of using dynamic external louvers in an office building. Energy and Buildings 42, 1888-1895.

Hirning, M., Isoardi, G.L., Coyne, S. Garcia Hansen, V.R, Cowling, I. (2013). Post occupancy evaluations relating to discomfort glare: a study of green 
buildings in Brisbane. Building and Environment 59, 349-357.

Hirning, M., Isoardi, G.L., Cowling, I. (2014). Discomfort glare in open plan green buildings. Energy and Buildings 70, 427-440.

Illuminating Engineering Society (IES) (2013). LM-8312: approved method: IES spatial daylight autonomy (sDA) and annual sunlight exposure (ASE).

Lo Verso, V.R.M., Mihaylov, G., Pellegrino, A., Pellerey, F. (2017). Estimation of the daylight amount and the energy demand for lighting for the early design stages: Definition of a set of mathematical models. Energy and Buildings 155, 151-165.

Mangkuto, R.A., Rohmah, A.D., Asri, A.D. (2016). Design optimisation of window size, orientation, and wall reflectance with regard to various daylight metrics and lighting energy demand: A case study of buildings in the tropics. Applied Energy 164, 211-219.

Mangkuto, R.A., Asri, A.D., Rohmah, M., Soelami, F.X.N. Soegijanto, R.M. (2016). Revisiting the national standard of daylighting in Indonesia: a study of five daylit spaces in Bandung. Solar Energy 126, 276-290.

Mangkuto, R.A., Kurnia, K.A., Azizah, D.N., Atmodipoero, R.T., Soelami, F.X.N. (2017). Determination of discomfort glare criteria for daylit space in Indonesia. Solar Energy 149, 151-163.

Ochoa, C.E., Aries, M.B.C., van Loenen, E.J., Hensen, J.L.M. (2012). Considerations on design optimization criteria for windows providing low energy consumption and high visual comfort. Applied Energy 95, 238-245.

Pigg, S., Eilers, M., Reed, J. (1996). Behavioral aspects of lighting and occupancy sensors in private offices: a case study of a university office building. Proceedings of the 1996 ACEEE Summer Study on Energy Efficiency in Buildings 8, 8.161-8.171.

Reinhart, C.F. (2004). Lightswitch-2002: a model for manual and automated control of electric lighting and blinds. Solar Energy 77, 15-28.

Reinhart, C.F., Jakubiec, J.A., Ibarra, D. (2013). Definition of a reference office for standardized evaluations of dynamic façade and lighting technologies. Proceedings of the $13^{\text {th }}$ Conference of International Building Performance Simulation Association, 3645-3652.

Tukey, J (1949). Comparing individual means in the analysis of variance. Biometrics 5, 99-114.

Van Dijk, D., Platzer, W.J. (2003). Reference office for thermal, solar and lighting calculations, Report no. swift-wp3-tno-dvd-030416. International Energy Agency (IEA) Task 27.

Wienold, J., Christoffersen J. (2005). Towards a new daylight glare rating. Proceedings of the 10th European Lighting Conference - Lux Europa 2005, Berlin (Germany), 19-21 September 2005.

Wienold, J., Christoffersen, J. (2006). Evaluation methods and development of a new glare prediction model for daylight environments with the use of CCD cameras. Energy and Buildings 38, 743-757.

Zhang, A., Bokel, R., van den Dobbelsteen, A., Sun, Y., Huang, Q., Zhang, Q. (2017). Optimization of thermal and daylight performance of school buildings based on a multi-objective genetic algorithm in the cold climate of China. Energy and Buildings 139, 371-384. 